\title{
Methods of the competence card application
}

\author{
Bychkovskyi V., Reutska Yu. \\ National Technical University of Ukraine "Igor Sikorsky Kyiv Polytechnic Institute", Kyiv, Ukraine
}

Received: $20.12 .2018 \quad$ Accepted: 27.12 .2018

\begin{abstract}
The methodology, which provides for the integrated use of the competency map and evaluation of personnel based on quality indicators is considered in this work. The expedient sequence of using competency maps of general and vocational directions is given. The features of the use of the competency map and its analogue in the form of a performance assessment chart have been analyzed. The need to use standardized indicators to ensure quantitative analysis is established. The procedure of multi-stage use of the competency map with the ranking of individual competencies and with additional verification of the obtained results is shown. The expertise methodology at each of the comparison stages of the ideal and real competency cards is reviewed. A comparative analysis of the ideal and realistic competence maps is considered. The method of estimating the value of the development area, which involves the use of relative quantities, is proposed. The quota system, which is based on ranking of results, distribution of assessments and the ratio between quotas and relative values of human development areas, has been formulated. In the process of conducting experimental studies identified the best, worst and average relative values of the areas of development. A procedure for the final determination of the relative values of the development area, based on additional verification of the results with the greatest deviations, is shown. On the basis of experimental data typical ranges of relative values of areas of development are defined. The comparative analysis of the results obtained at the various stages of the assessment of the personnel has been completed. The prediction model of transition from lower to higher level of competence is proposed. The regularity of the change in the relative error is determined depending on the initial condition, the potentially possible minimum value of the error, the individual personality characteristics and the studying time. The time required to go from the lowest competence level to the highest competence level is established. The relationship between the personal characteristics of the individual, the studying time and the studying effectiveness is determined.
\end{abstract}

Key words: evaluation of personnel, competency map, quantitative characteristics, self-examination, development forecasting.

\section{Методика застосування карти компетенцій}

Бичковський В. О., Реутська Ю. Ю.

Національний технічний університет України “Київський політехнічний інститут імені Ігоря Сікорського”, Київ, Україна

Анотація. У роботі розглянуто методику, яка передбачає комплексне застосування карти компетенцій та проведення оцінки персоналу на підставі якісних показників. Показана доцільна послідовність використання карт компетенцій загальної та професійно-технічної спрямованостей. Проаналізовані особливості застосування карти компетенцій та її аналога у вигляді діаграми оцінки ефективності. Встановлено необхідність використання нормованих показників для забезпечення кількісного аналізу. Показана процедура багатоетапного використання карти компетенцій на підставі ранжування окремих компетенцій з додатковою верифікацією отриманих результатів. Розглянуто методику експертизи на кожному з етапів порівняння ідеальної та реальної карт компетенцій. Проведено порівняльний аналіз ідеальної та реальної карт компетенцій. Запропоновано методику оцінки величини області розвитку, яка передбачає використання відносних величин. Складено систему квот, яка базується на ранжуванні результатів, розподілі оцінок та співвідношенні між квотами та відносними значеннями областей розвитку персоналу. В процесі проведення експериментальних досліджень визначено найкраще, найгірше та середнє відносні значення областей розвитку. Показана процедура остаточного з'ясування відносних значень області розвитку, яка базується на додатковій верифікації результатів, що мають найбільші відхилення. На підставі експериментальних даних

\footnotetext{
Corresponding Author: Reutska Yuliia Yuriivna. Tel. +38(093) 547-58-02. E-mail: reutska_rt@ukr.net National Technical University of Ukraine «lgor Sikorsky Kyiv Polytechnic Institute», Vul. Politechnical, 12, 17th building of NTUU «KPI them. Igor Sikorsky», Kyiv, Ukraine, 03056.

Відповідальний автор: Реутська Юлія Юріївна. Тел. +38(093) 547-58-02. E-mail: reutska_rtf@ukr.net Національний технічний університет України «Київський політехнічний інститут імені Ігоря Сікорського», вул. Політехнічна 12, 17-й корпус НТУУ «КПІ ім. Ігоря Сікорського», Київ, Україна, 03056.
} 
визначені типові діапазони відносних значень областей розвитку та виконано порівняльний аналіз результатів, отриманих на різних етапах оцінки персоналу. Запропоновано прогнозну модель переходу від нижчого до вищого рівня компетентності. Визначено закономірність зміни відносної помилки в залежності від початкової умови, потенційно можливого мінімального значення помилки, індивідуальної характеристики особистості та часу навчання. Встановлено час, необхідний для переходу від нижчого до вищого рівня компетентності. Визначено взаємозв'язок між індивідуальною характеристикою особистості, часом навчання та результативністю навчання.

Ключові слова: оцінка персоналу, карта компетенцій, кількісні характеристики, самоаналіз, прогнозування розвитку.

\title{
Методика применения карты компетенций
}

\author{
Бычковский В. А., Реутская Ю. Ю. \\ Национальный технический университет Украины "Киевский политехнический институт имени Игоря Сикорского", Киев, \\ Украина
}

\begin{abstract}
Аннотация. В работе рассмотрена методика, которая предусматривает комплексное применение карты компетенций и проведение оценки персонала на основании качественных показателей. Приведена целесообразная последовательность использования карт компетенций общего и профессиональнотехнического направленностей. Проанализированы особенности применения карты компетенций и ее аналога в виде диаграммы оценки эффективности. Установлена необходимость использования нормированных показателей для обеспечения количественного анализа. Показана процедура многоэтапного использования карты компетенций на основании ранжирования отдельных компетенций с дополнительной верификацией полученных результатов. Рассмотрена методика экспертизы на каждом из этапов сравнения идеальной и реальной карт компетенций. Проведен сравнительный анализ идеальной и реальной карт компетенций. Предложена методика оценки величины области развития, которая предусматривает использование относительных величин. Составлена система квот, которая базируется на ранжировании результатов, распределении оценок и соотношении между квотами и относительными значениями областей развития персонала. В процессе проведения экспериментальных исследований определены лучшее, худшее и среднее относительные значения областей развития. Показана процедура окончательного выяснения относительных значений области развития, основанная на дополнительной верификации результатов, имеющих наибольшие отклонения. На основании экспериментальных данных определены типичные диапазоны относительных значений областей развития и выполнен сравнительный анализ результатов, полученных на различных этапах оценки персонала. Предложена прогнозная модель перехода от низшего к высшему уровню компетентности. Определена закономерность изменения относительной ошибки в зависимости от начального условия, потенциально возможного минимального значения ошибки, индивидуальной характеристики личности и времени обучения. Установлено время, необходимое для перехода от низшего к высшему уровню компетентности. Определена взаимосвязь между индивидуальной характеристикой личности, временем обучения и результативностью обучения.
\end{abstract}

Ключевые слова: оценка персонала, карта компетенций, количественные характеристики, самоанализ, прогнозирование развития.

\section{Bcmyn}

Успішне працевлаштування за фахом випускників вищих навчальних закладів залежить від багатьох складових. Приймаючи на роботу нового співробітника, керівник завжди оцінює його за тими або іншими критеріями, з'ясовуючи відповідність бажаних та дійсних можливостей кандидата. Досить часто вимоги до фахівців $є$ досить нечіткими або недостатньо формалізованими. В результаті через деякий час у керівника наступає період сумнівів, а потім і розчарування. Приймаючи до уваги цей факт, все більше керівників починають застосовувати сучасні методи оцінки персоналу [1, 2]. Оцінка персоналу - це система, яка дає можливість об'єктивно визначити рівень професійної підготовки кандидатів на посаду або співробітників та їх потенційні можливості.

3 метою правильної постановки задачі перевірки кандидатів на посаду в організаціях розробляється профіль посади, тобто опис компетенцій, досвіду та анкетних даних, необхідних для виконання даної роботи в даній організації. 


\section{II Матеріал і методи дослідження}

При складанні профілю посади важливе місце займає складова, яка враховує очікування від нового співробітника у відповідності до корпоративної культури організації. Керівники організації складають профріль посади в наступній послідовності:

1.Вибирають із загального переліку компетенцій ті, що відносяться до обов'язкових, та ранжирують значимість тих або інших фракторів.

2. Вибирають із загального переліку компетенцій ті з них, які найбільш сподобаються у вже працюючих співробітниках.

3. Вибирають ті фактори, які не сподобаються у вже працюючих співробітниках.

Кожна компетенція формулюється у конкретному вигляді і може мати різну вагу. На підставі ряду компетенцій складається карта потрібних компетенцій (ідеальний профіль). Після перевірки кандидата на посаду складається реальна карта компетенцій (реальний профіль). В результаті порівняння обох карт визначається область розвитку та приймається рішення про доцільність використання кандидата на даній посаді [1]. В залежності від конкретної ситуації передбачається використання карт компетенцій (КК) загальної спрямованості (ККЗС) та професійно-технічної спрямованості (ККПТС). Слід вважати доцільним використання ККЗС на першому етапі перевірки кандидатів на посаду та ККПТС на подальших етапах.

Необхідно зауважити, що у карти компетенцій $є$ аналог у вигляді діаграми оцінки ефективності (ДОЕ) [3]. Як ДОЕ, так і КК аналізуються на підставі абсолютних значень величин ділянок, з яких вони складаються. Такий підхід не є раціональним, оскільки він забезпечує якісний, а не кількісний аналіз. Відомо, що для проведення кількісного аналізу доцільно використовувати нормовані показники [4]. Але як при використанні КК так і ДОЕ ця процедура не розглядається. Таким чином, визначення компетенцій за кількісними показниками є актуальною задачею. Методика застосування карти компетенцій повинна передбачати можливість прогнозування результатів навчання та розвитку.

Виходячи з актуальності задачі використання карти компетенцій представляється доцільним:

1. Проаналізувати типові оціночні шкали та визначитися з найбільш раціональними їх варіантами.

2. Вибрати методику ранжування окремих компетенцій.

3. Визначитися з методикою оцінки величини області розвитку.

4. Розробити методику верифрікації отриманих результатів.

Порівняльний аналіз ідеальної та реальної карт компетенцій повинен давати можливість оцінити як реальні, так і потенційні можливості кандидата на посаду. Необхідно з'ясувати принцип переходу від відносних значень величин областей розвитку до системи квот та оцінки необхідного об'єму додаткових знань та компетенцій.

Для складання КК необхідно визначитися з вагою кожної компетенції, тобто вибрати оціночні шкали. В наш час використовують різні оціночні шкали: двобальну, трьохбальну, п'ятибальну, семибальну, десятибальну, дванадцятибальну [1]. Будемо використовувати п'ятибальну систему (А, B, C, D, E), яка в процесі оцінки кандидатів трактується наступним чином:

A. Видатний - виключно високий рівень, який перевищує сподівання організації.

В. Відмінний - дуже високий рівень, повна відсутність зауважень, глибокі професійні знання. Відповідає високим очікуванням організації.

C. Добрий - повна відповідність посаді.

D. Прийнятний - не зовсім відповідає очікуванням.

E. Неприйнятний - негативна оцінка.

В якості базисної оцінки вибирається середня по шкалі оцінка «С», тобто повна відповідність посаді [1].

Аналіз рівня підготовки студентів виконувався в декілька етапів. На першому етапі аналізу використовувалась ККЗС із чотирьох компетенцій (ККЗС-4): інтелектуальний рівень, працездатність, володіння мовами, рівень професійної підготовки. Інтелектуальний рівень та працездатність оцінювались на підставі стандартних методик [5]. Володіння мовами та рівень професійної підготовки оцінювались відповідно до оцінок, отриманих під час навчання. На другому етапі використовувалась ККПТС-4. Студентам було запропоновано виконати ранжування дисциплін випускаючої кафедри з точки 
зору їх практичної значимості у подальшому працевлаштуванні за фахом, вибрати чотири найвагоміших з них та скласти ідеальну карту компетенцій. Складені таким чином ідеальні ККПТС-4 здавалися експерту.

На третьому етапі експерт повертав ККПТС-4 студентам та запропоновував скласти реальну карту компетенцій і визначити відносне значення області розвитку $\gamma_{1}$.

На четвертому етапі експерт проводив аналіз всіх ідеальних ККПТС-4, отриманих на другому етапі, та складав уточнюючу ідеальну ККПТС-4, яка враховувала висновки всіх студентів.

На п'ятому етапі студенти складали уточнюючу реальну ККПТС-4, та визначали відносне значення області розвитку $\gamma_{2}$.

Передбачався також додатковий етап для верифікації отриманих результатів.

\section{III Результати}

Аналіз отриманих даних на третьому етапі дав можливість зробити наступні висновки:

1. Найкраще відносне значення області розвитку $\gamma_{1 K}=0,1$.

2. Найгірше відносне значення області розвитку $\gamma_{1 \tilde{A}}=0,58$.

3. Середнє відносне значення області розвитку $\gamma_{1 \tilde{N}}=0,36$.

Аналіз отриманих результатів на п'ятому етапі дав наступні результати:

1. Найкраще відносне значення області розвитку $\gamma_{2 K}=0,1$.

2. Найгірше відносне значення області розвитку $\gamma_{2 \tilde{A}}=0,46$.

3. Середнє відносне значення області розвитку $\gamma_{2 \tilde{N}}=0,31$.

Порівняльний аналіз результатів, отриманих на третьому та п'ятому етапах показує, що найбільше відрізняються значення $\gamma_{1 \Gamma}$ та $\gamma_{2 \Gamma} .3$ метою остаточного з'ясування відносних значень області розвитку проводилась додаткова верифрікація. Для цього на підставі даних другого етапу визначалися дисципліни із загального переліку, запропонованого студентами, які відмічалися найчастіше. З'ясувалося, що таких дисциплін шість, тобто треба використовувати ККПТС-6. Порівняльний аналіз ідеальних та реальних ККПТС-6 дав наступні результати щодо відносних значень $\gamma_{3}$ області розвитку:

1. Найкраще відносне значення області розвитку $\gamma_{3 к}=0,12$.

2. Найгірше відносне значення області розвитку $\gamma_{3 \tilde{A}}=0,46$.

3. Середнє відносне значення області розвитку $\gamma_{3 \tilde{N}}=0,33$.

Приймаючи до уваги, що дані другого та третього етапів базуються на результатах самоаналізу, можна зробити висновок, що найгірше відносне значення області розвитку ближче до $\gamma_{3 \tilde{A}}=0,46$.

\section{IV Обговорення}

На підставі ранжування отриманих результатів складається система квот, для чого задається розподіл оцінок. Для п'ятибальної системи вона виглядає наступним чином: «А» $-5 \%$, «В» - $15 \%$, «C»-60 \%, «D»- $15 \%$, «E» - 5 \% [1]. Процедура ранжування зводилась до того, що порівнювалися всі результати від найкращого до найгіршого. Тоді найкращі $5 \%$ результатів оцінюються як «А», наступні $15 \%$ - як «В», далі, відповідно, як « $\mathrm{C} », ~ « D », ~ « Е »$.

Моніторинг відносних значень області розвитку всіх етапів та додаткової верифікації дав можливість встановити співвідношення між цим показником та відповідними оцінками:
А. Відносне значення області розвитку від 0 до 0,12.
В. Відносне значення області розвитку від 0,12 до 0,23.
C. Відносне значення області розвитку від 0,23 до 0,42.
D. Відносне значення області розвитку від 0,42 до 0,46.
Оцінка «Е» кваліфікується як негативна (відносне значення області розвитку більше 0,46 ). 
Відносне значення області розвитку є підставою для складання індивідуального плану навчання та підвищення професійної майстерності кандидата на посаду [1].

Можливими формами навчання слід вважати наступні:

1. Участь у внутрішніх та зовнішніх семінарах, тренінгах, друга вища освіта.

2. Дистанційні курси.

3. Самостійна робота з літературою та іншими джерелами інформації.

До можливих форм розвитку відносять:

1. Стажування.

2. Самостійне проведення семінарів та конференцій.

3. Участь у конгресах та конференціях.

4. Участь у корпоративних проектах.

Навчання та розвиток не представляються можливими без використання інформації різноманітного характеру: кореспондентської, технічної, параметричної, випереджаючої, словесної, візуальної [6]. Використання необхідних джерел інформації забезпечує підвищення рівня претендента на вакантну посаду. Згідно закону великих чисел П. Л. Чебишева мінімальна необхідна кількість джерел інформації $V_{\text {min }}$, яка забезпечує відносну помилку $\gamma$, визначається за формулою $V_{\min }=4 b / \gamma$. Коефріцієнт $b$ знаходиться в межах від 5 до 7. Таким чином, після проведення аналізу за допомогою карти компетенцій кожний кандидат на вакантну посаду має можливість самостійно визначитися 3 об'ємом джерел інформації, які треба проробити для забезпечення необхідного значення $\gamma$.

Приймемо до уваги, що протягом часу навчання величина $\gamma$ постійно зменшується та асимптотично наближається до свого потенційно можливого мінімального значення $\gamma_{\min }$. Якщо $K-$ константа швидкості зміни $\gamma$, то можна записати,

$$
d \gamma=-K\left(\gamma-\gamma_{\min }\right) d t
$$

На підставі рівняння (1) знаходимо,

$$
\frac{d \gamma}{\gamma-\gamma_{\min }}=-K d t
$$

Нехай $\gamma_{0}-$ початкове значення відносної помилки. Інтегруючи ліву частину рівняння (2) від $\gamma_{0}$ до $\gamma$, а праву від 0 до $t$, визначаємо закономірність зменшення відносної помилки,

$$
\gamma=\gamma_{\min }+\left(\gamma_{0}-\gamma_{\min }\right) \exp (-K t) .
$$

Аналіз залежності (3) показує, що для заданих $\gamma_{0}$ та $\gamma_{\min }$ досягнути необхідного значення $\gamma$ можна за умови певного значення $K t$. Отже, для великих значень $K$ необхідне значення $\gamma$ забезпечується за менший час $t$, і навпаки (рис. 1). Протягом часу відношення $\gamma / \gamma_{0}$ зменшується та асимптотично наближається до величини $\gamma_{\min } / \gamma_{0}$.

На підставі залежності (3) можна визначити час, необхідний для зменшення відносної помилки від $\gamma_{0}$ до $\gamma$ :

$$
t=\frac{1}{K} \ln \frac{\gamma_{0}-\gamma_{\min }}{\gamma-\gamma_{\min }}
$$

Приймаючи до уваги фрормулу (3), знаходимо $d \gamma / d t$ в точці $t=0$ :

$$
\left.\frac{d \gamma}{d t}\right|_{t=0}=-K\left(\gamma_{0}-\gamma_{\min }\right) \text {. }
$$

Аналіз залежності (5) показує, що величина $1 / \mathrm{K}$ у формулі (4) відповідає моменту часу, коли дотична до кривої $\gamma=\gamma(t)$ в точці $t=0$ перетинає рівень $\gamma=\gamma_{\min }$. Таким чином, існує можливість прогнозування зміни $\gamma$, а величину К можна розглядати як індивідуальну характеристику кандидата. 


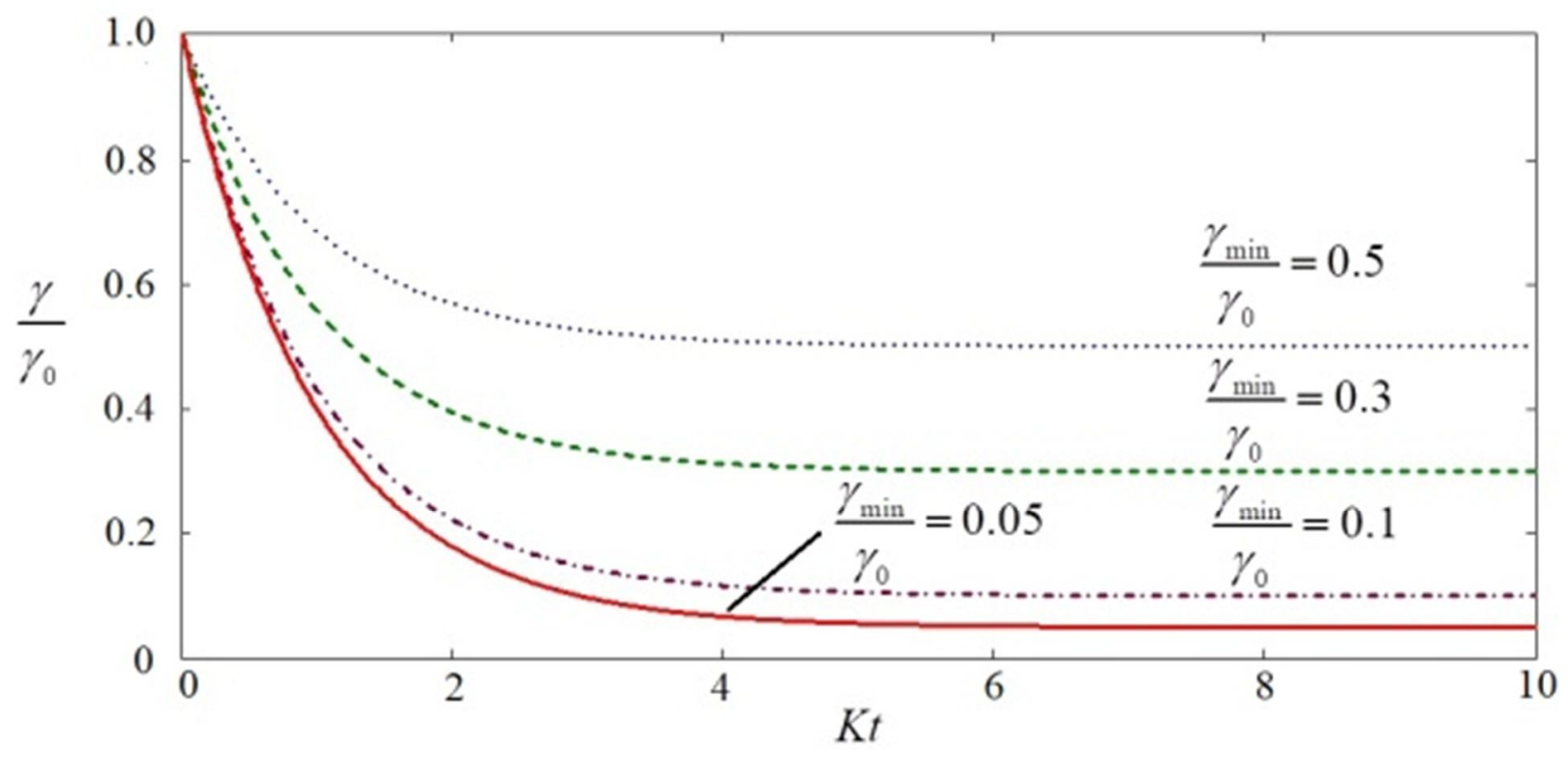

Рис. 1. Закономірність зміни нормованого значення відносної помилки

\section{V Висновки}

Практика використання карти компетенцій для оцінки рівня професійної підготовки кандидатів на вакантну посаду показує, що існує реальна можливість забезпечити комплексний підхід до визначення їх можливостей, напрямів та перспектив розвитку. При складанні профілю посади доцільно ранжувати найбільш важливі компетенції або вибирати із загального переліку такі, які мають найбільше значення. В процедурі застосування карти компетенцій необхідно передбачати етапи верифікації, які дають можливість підвищити достовірність отриманих результатів. Ранжування результатів дає можливість скласти систему квот, яка основується на розподілі оцінок, та визначити співвідношення між квотами та відносними значеннями областей розвитку. На підставі аналізу відносних значень областей розвитку представляється можливим визначити необхідні форми навчання та індивідуального розвитку кандидата на вакантну посаду. Після аналізу за допомогою карти компетенцій кожний фахівець може самостійно визначитися з основними формами додаткового навчання та необхідним для вивчення об'ємом джерел інформації.

Приймемо до уваги, що компетентнісний підхід $є$ ключовим у процесі удосконалення вищої освіти в Україні $[7,8]$. Таким чином, запропонована методика може використовуватися як для оцінювання профресійної компетентності, так і у навчальному процесі або для проведення самоаналізу. Процедура застосування карти компетенцій може базуватися на комплексному підході. На одному з етапів доцільно використовувати відомі методи оцінки та атестації персоналу [9, 10, 11]. На іншому - розглянуту методику. Достовірність отриманих результатів буде збільшена в разі використання декількох математичних моделей [12]. На підставі аналізу відношення $\gamma / \gamma_{0}$ представляється можливим визначати ефективність технологій коучингу та результативність тренінгу [13, 14]. Запропонована методика застосування карти компетенцій доповнюе існуючі підходи до визначення компетентності персоналу [15]. Вона дає можливість прогнозувати результативність самовдосконалення та самоосвіти [16, 17]. Багатоетапне використання карти компетенцій забезпечує можливість об'єктивної оцінки рівня підготовки студентів $[18,19,20]$. Така процедура може бути доцільною в разі атестації фахівців. 


\section{Бібліографічні посилання}

[1] Вулкович-Стадник А. А. Оценка персонала: четкий алгоритм действий и качественные практические решения. М. : Эксмо, 2008. 192 с.

[2] Иванова С. В. Кандидат, новичок, сотрудник. Инструменты управления персоналом, которые реально работают на практике. М. : Эксмо, 2008. 304 с.

[3] Соловьев М. В., Корольков Г. Н., Бараненко А. А. и др Морская радиоєлектроника: справочник; под ред. В. А. Кравченко. СПб: Политехника, 2003. 246 с.

[4] Згуровський М. З., Панкратова Н. Д. Основи системного аналізу. К. : Видавнича група ВНV, 2007. 544 с.

[5] Кебадзе С. В., Карпенко Н. Ф., Мироненко О. В., Пекур А. В., Пекур В. Н. Избранные психологические тесты для профотбора и профориентации абитуриентов, студентов и молодых специалистов. К. : КПИ, 1992. 94 с.

[6] Кузнєцов Ю. М., Скляров Р. А. Прогнозування розвитку технічних систем. К. : ТОВ «ЗМОК» - ПП «ГНОЗИС», 2004. $323 \mathrm{c.}$.

[7] Воробієнко П., Ложковський А. Компетентнісний підхід у вищій освіті - від теорії до практики / Вища школа, 2016 . № 6. C. 13-20.

[8] Компетентнісний підхід у сучасній освіті: світовий досвід та українські перспективи; під. заг. ред. О. В. Овчарук. К.: «K.I.C.», 2004. $112 \mathrm{C}$.

[9] Bienzeisler, Bernd (2005). Die Competence Card als Mess- und Steuerungsinstrument für die Dienstleistungswirtschaft. Praxishandbuch Controlling, 167-183. https://doi.org/10.1007/978-3-322-90505-5_6

[10] Борисова Е. А. Оценка и аттестация персонала. СПб : Питер, 2002. 256 с.

[11] Дрешер Ю. Н. Как оценить качество подготовки специалистов / Образовательные технологии, 2014. № 2. С. $80-91$.

[12] Далингер В. А. Измерение качества профессиональной подготовки специалиста с помощью математической модели Раша / Современные наукоемкие технологии, 2007. № 11. С. 47-48.

[13] Гаврилюк Г. В. Подготовка и повышение компетенций кадров с использованием технологий и структур коучинга / Новые технологии, 2010. № 4. С. 74-76.

[14] Шевцова И. В. Тренинг личностного роста. СПб.: Речь, 2003. 144 с.

[15] Уиддет Стив, Холлифорд Сара. Руководство по компетенциям; Пер. с англ. М.: ГИППО, 2008. 228 с.

[16] Стивен Р. Кови. Семь навыков высокоэффективных людей; Пер. с англ. М.: Альпина Паблишер, 2018. 396 с.

[17] Кауфман Д. Сам себе МВА. Самообразование на 100 \%; Пер. с англ. М.: Манн, Иванов и Фербер, 2016. 464 с.

[18] Ashima Aggarwal, Gour Sundar Mitra Thakur (2013). Techniques of Performance Appraisal-A Review, 617-621. International Journal of Engineering and Advanced Technology (IJEAT) ISSN: 2249 - 8958, Volume-2, Issue-3, February. https://pdfs.semanticscholar.org/dfcb/3490e4a5e999263339ef27d76548f1440410.pdf

[19] Heljä Hätönen (2014) Competence Map for Workplace Instructors Print Juvenes Print - Suomen Yliopistopaino Oy, Tampere, ISBN 978-952-13-5672-8 37 p.

https://www.oph.fi/download/155784_competence_map_for_workplace_instructors.pdf

[20] Baughman, Jacqulyn, (2012) Student professional development: Competency-based learning and assessment in an undergraduate industrial technology course. Graduate Theses and Dissertations. lowa State University Ames, lowa. https://lib.dr.iastate.edu/cgi/viewcontent.cgi?referer=https:/www.google.com/\&httpsredir=1\&article=3599\&context=etd

\section{References}

[1] Vulkovich-Stadnik, A. A. (2008). Ocenka personala: chetkij algoritm dejstvij i kachestvennye prakticheskie resheniya, Eksmo, Moscow, Russia. [in Russian]

[2] Ivanova, S. V. (2008). Kandidat, novichok, sotrudnik. Instrumentyi upravleniya personalom, kotoryie realno rabotayut na praktike. Eksmo, Moscow, Russia. [in Russian]

[3] Solovev, M. V., Korolkov, G. N., Baranenko, A. A. etc. (2003). Morskaya radioelektronika. Spravochnik. Edited by Kravchenko V.A. Politehnika, Saint Petersburg. [in Russian]

[4] Zghurovskyi, M. Z, Pankratova, N. D. (2007). Osnovy systemnoho analizu, Vydavnycha hrupa BHV, Kyiv. [in Ukrainian]

[5] Kebadze, S. V., Karpenko, N. F., Mironenko, O. V., Pekur, A. V., Pekur, V. N. (1992). Izbrannyie psihologicheskie testyi dlya profotbora i proforientatsii abiturientov, studentov i molodyih spetsialisto, Polytechnic Institute, Kyiv. [in Russian]

[6] Kuznietsov, Yu. M., Skliarov, R. A. (2004) Prohnozuvannia rozvytku tekhnichnykh system, TOV «ZMOK» - PP «HNOZYS», Kyiv. [in Ukrainian]

[7] Vorobiienko, P., Lozhkovskyi, A. (2016) Kompetentnisnyi pidkhid u vyshchii osviti - vid teorii do praktyky, periodical Vyshcha shkola Iss. 6, pp. 13-20. [in Ukrainian]

[8] Kompetentnisnyi pidkhid u suchasnii osviti: svitovyi dosvid ta ukrainski perspektyvy. Biblioteka z osvitnoi polityky. (2004) Edited by Ovcharuk O.V., «K.I.S.». in Ukrainian]

[9] lenzeisler, Bernd (2005). Die Competence Card als Mess- und Steuerungsinstrument für die Dienstleistungswirtschaft. Praxishanbuch Controlling, 167-183. https://doi.org/10.1007/978-3-322-90505-5_6

[10] Borisova, E. A. (2002) Otsenka i attestatsiya personala. SPb : Piter, Russia. [in Russian]

[11] Dresher, Yu. N. (2014). Kak otsenit kachestvo podgotovki spetsialistov, periodical Obrazovatelnyye tekhnologii. Iss. 2. pp. 80-91. [in Russian]

[12] Dalinger, V. A. (2007) Izmereniye kachestva professionalnoy podgotovki spetsialista s pomoshchyu matematicheskoy modeli Rasha, periodical Sovremennyye naukoyemkiye tekhnologii. Iss. 11. pp. 47-48. [in Russian] 
[13] Gavrilyuk, G. V. (2010) Podgotovka i povysheniye kompetentsiy kadrov s ispolzovaniyem tekhnologiy i struktur kouchinga, periodical Novyye tekhnologii. Iss. 4. pp. 74-76. [in Russian]

[14] Shevtsova, I. V. (2003) Trening lichnostnogo rosta. SPb.: Rech, Saint Petersburg, Russia. [in Russian]

[15] Uiddet, Stiv and Kholliford, Sara. (2008) Rukovodstvo po kompetentsiyam; Per. s angl. GIPPO, Moscow, Russia. [in Russian]

[16] Stiven, R. Kovi. (2018) Sem navykov vysokoeffektivnykh lyudey, Per. s angl. Moscow: Alpina Pablisher. Russia. [in Russian]

[17] Kaufman, D. (2016) Sam sebe MBA. Samoobrazovaniye na 100 \%; Per. s angl. Moscow: Mann. Ivanov i Ferber. Russia. [in Russian]

[18] Ashima Aggarwal, Gour Sundar Mitra Thakur (2013). Techniques of Performance Appraisal-A Review, 617-621. International Journal of Engineering and Advanced Technology (IJEAT) ISSN: 2249 - 8958, Volume-2, Issue-3, February. https://pdfs.semanticscholar.org/dfcb/3490e4a5e999263339ef27d76548f1440410.pdf

[19] Heljä Hätönen (2014) Competence Map for Workplace Instructors Print Juvenes Print - Suomen Yliopistopaino Oy, Tampere, ISBN 978-952-13-5672-8 $37 \mathrm{p}$.

https:/www.oph.fi/download/155784_competence_map_for_workplace_instructors.pdf

[20] Baughman, Jacqulyn, (2012) Student professional development: Competency-based learning and assessment in an undergraduate industrial technology course. Graduate Theses and Dissertations. Iowa State University Ames, lowa. https://ib.dr.iastate.edu/cgi/viewcontent.cgi?referer=https://www.google.com/\&httpsredir=1\&article=3599\&context=etd

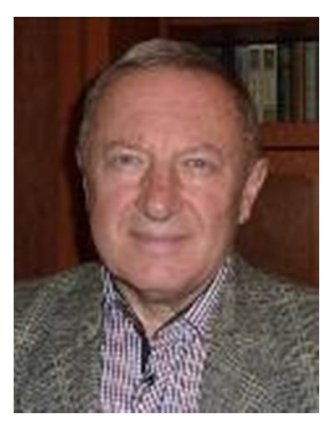

\section{Бичковський Владислав Олексійович,}

к.техн.н., доцент, доцент кафедри радіотехнічних пристроїв та систем, Національний технічний університет України «Київський політехнічний інститут імені Ігоря Сікорського», вул. Політехнічна 12, 17-й корпус НТУУ «КПІ ім. Ігоря Сікорського», Київ, Україна, 03056. Тел. +38(050) 163-75-88. E-mail: marina060709@gmail.com

\section{Bychkovskyi Vladyslav Oleksiyovych,}

Cand.Sc. (Eng.), Associate Professor, Associate Professor of Radiotechnical Devices and Systems Department, National Technical University of Ukraine «lgor Sikorsky Kyiv Polytechnic Institute» Vul. Politechnical, 12, 17th building of NTUU «KPI them. Igor Sikorsky», Kyiv, Ukraine, 03056. Tel. +38(050) 163-75-88. E-mail: marina060709@gmail.com

ORCID: 0000-0003-1065-4924

Researcher ID: I-4729-2018

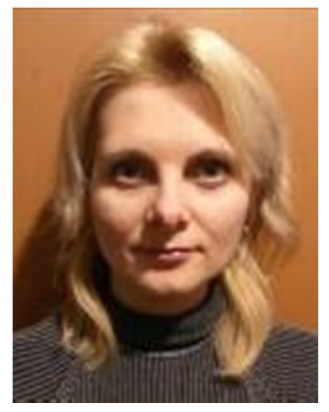

\section{Реутська Юлія Юріївна,}

старший викладач кафеедри радіотехнічних пристроїв та систем, Національний технічний університет України «Київський політехнічний інститут імені Ігоря Сікорського», вул. Політехнічна 12, 17-й корпус НТУУ «КПІ ім. Ігоря Сікорського», Київ, Україна, 03056. Тел. +38(093) 547-58-02. E-mail: reutska_rtf@ukr.net

Reutska Yuliia Yuriivna,

Senior Lecturer of Radiotechnical Devices and Systems Department, National Technical University of Ukraine «lgor Sikorsky Kyiv Polytechnic Institute»?

Vul. Politechnical, 12, 17th building of NTUU «KPI them. Igor Sikorsky», Kyiv, Ukraine, 03056.

Tel. +38(093) 547-58-02. E-mail: reutska_rtf@ukr.net

ORCID: 0000-0003-1954-9100

Researcher ID: I-4652-2018

\section{Citation (APA):}

Bychkovskyi, V., Reutska, Yu. (2018). Methods of the competence card application. Engineering and Educational Technologies, 6 (4), 30-37. doi: https://doi.org/10.30929/2307-9770.2018.06.04.03

\section{Цитування (ДСТУ 8302:2015):}

Бичковський В. О., Реутська Ю. Ю. Методика застосування карти компетенцій / Інженерні та освітні технології. 2018. Т. 6. № 4. C. 30-37. doi: https://doi.org/10.30929/2307-9770.2018.06.04.03

\footnotetext{
Обсяг статmі: сторінок - 8 ; умовних друк. аркушів - 0,920.
} 